\title{
Tratado y Atlas de Colposcopia
}

La Sociedad Colombiana de Obstetricia y Ginecología ha recibido con destino a su biblioteca el TRATADO Y ATLAS DE COLPOSCOPIA por los Doctores J. M. Carrera, S. Dexeus y F. Coupez, gentilmente donado por sus autores.

El Profesor Rubén Darío Guzmán Alandete, Profesor de Obstetricia y Ginecología de la Universidad Nacional hace el siguiente comentario:

Los autores dividen la obra en 10 capítulos de gran interés. Es llamativa la forma como los autores hablan en el primer Capítulo de la historia de la Colposcopia y de los diferentes autores que le dieron auge a este procedimiento en los distintos países donde se iba conociendo. En él también trata de los diversos aparatos que existen, la ventaja de cada uno de ellos, la técnica operatoria a seguir, y los diferentes símbolos colposcópicos empleados por la escuela de Zunch, modificados por los autores de esta obra.

El Capítulo segundo describe las imágenes del cuello normal y el correspondiente estudio histológico.

De gran interés es el Capítulo tercero, el cual hace referencia a los aspectos colposcópicos e histológicos del cuello inflamatorio.

El Capítulo cuarto trata de la distrofia cervical haciendo hincapié que ésta lesión puede presentarse sobre cualquiera de los elementos que componen la mucosa que reviste el cuello uterino, de ahí el interés de los autores por una clasificación anatomopatológica que se refiera al elemento alterado (distrofia epitelial, glandular, estromática y vascular). Según ellos, esta clasificación tiene la ventaja de ser didáctica y hace que muchas lesiones no descritas se agrupen en ellas.

Los Capítulos quinto y sexto versan sobre la Ectopía Cervical y en ellos es interesante los diferentes aspectos colposcópicos de esta lesión, la evolución que pueda seguir pasando desde la reepitelización típica y la atípica hasta llegar el Ca. del cuello uterino.

El Capítulo séptimo es dedicado al cuello displásico. En él trata de la leucoplasia el mosaico y la base. Presentan una serie de láminas en colores donde puede apreciarse de una manera real estas lesiones.

De verdadero interés es el Capítulo octavo relacionado con el cuello neoplásico; en él trata las neoformaciones benignas y las malignas. Puede apreciarse en una forma clara las imágenes colposcópicas de los pólipos, papilomas, fibromas cervicales y del Ca. del cuello uterino.

El Capítulo noveno trata sobre la Colposcopia durante el embarazo. Nos pone de presente la necesidad de conocer una serie de imágenes colposcópicas para no caer en lamentables errores de intrepretación pues son muy fáciles de confundirlos con una lesión neoplásica in situ del cuello uterino. 
Por último el Capítulo décimo versa sobre la colposcopia práctica. Los autores presentan un resumen práctico y esquemático de las diferentes etapas del examen colposcópico aplicado a los aspectos cervicales más frecuentemente observados y nos ponen de presente todos los requisitos y medios que se requieren para lograr éxito con este procedimiento.

Quiero recalcar las excelentes imágenes colposcópicas obtenidas por medio de las colpofotografías correlacionándolas con los aspectos histológicos y anatomoclínicos; además es plausible la presentación de la obra de la casa editora.

Por todo lo expuesto anteriormente, nos hace recomendar de una manera sincera y loable el Tratado y Atlas de Colposcopia de los Doctores J. M. Carrera, S. Dexeus y F. Coupez, como un libro que todo ginecólogo interesado en este tema debe tenerlo en su servicio, ya que sin lugar a duda es una obra que figurará entre las primeras que tratan sobre tal procediminto no solo en nuestro medio sino universalmente.

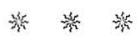

Los padres de niños sordos o ciegos pueden recibir ayuda por medio del

\section{Programa de Enseñanza por Correspondencia}

desarrollado por la Clínica John Tracy. Se edita en inglés y en español. A través de un intercambio de cartas personales, con la familia, la Clínica establecerá programas individuales para las necesidades de cada niño. El programa es gratis para los padres de niños sordos o ciegos.

Los profesionales pueden conseguir copias del curso a US \$9.50.

La correspondencia debe dirigirse a:

John Tracy Clinic, 806 West Adams,

Los Angeles, California 90007.

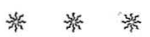

\section{Congreso de la Federación de las Sociedades de Obstetricia y Ginecología de la Lengua Francesa}

\section{Septiembre 24 de 1974}

\section{Temas:}

1) CANCER

2) CONTRACEPCION

3) INFERTILIDAD

4) PERINATOLOGIA

Informes:

Secretaría General del XXV Congreso

2065 Rue Alexandre de Séve, Chambre 202,

Montreal H2L 4Ml, Quebec, Canadá 